
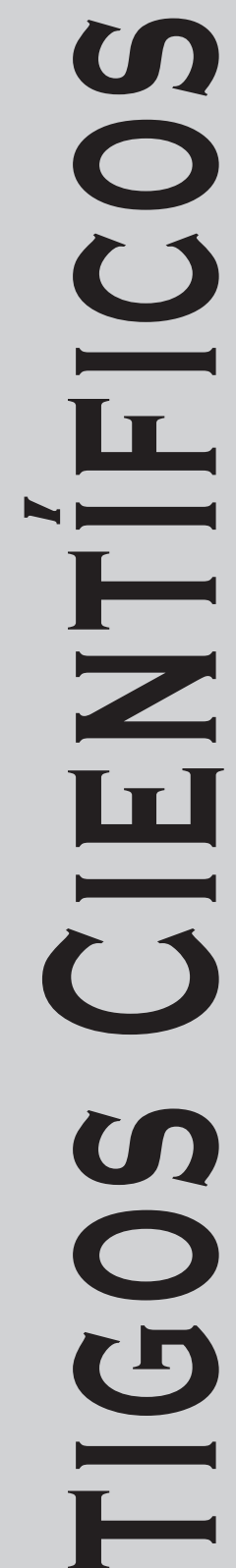
ac

Revista Música Hodie, Goiânia - V.14, 238p., n.1, 2014 


\title{
Referenciais Teóricos da Música Eletroacústica Brasileira e a Influência das Matrizes Históricas
}

\author{
Rodrigo Cicchelli Velloso (Universidade Federal do Rio de Janeiro, Rio de Janeiro, RJ) \\ rodcv@acd.ufrj.br \\ Frederico Machado de Barros (Universidade Federal do Rio de Janeiro, Rio de Janeiro, RJ) \\ frederico.mb@gmail.com
}

\begin{abstract}
Resumo: Neste estudo, empreendemos uma avaliação acerca da influência de três matrizes históricas da música eletroacústica - Musique Concrète, Elektronische Musik e Computer Music - sobre a produção brasileira de música eletroacústica. O alcance desta influência no país é avaliado por meio da aplicação de um questionário que visa a mapear, entre outros aspectos, desde o caráter da produção dos compositores nos últimos cinco anos até que obras teóricas ligadas a estas três correntes foram lidas, bem como que conceitos daí originados teriam maior influência no pensamento composicional dos respondentes. A partir da análise das respostas ao questionário, algumas considerações são feitas e questões são levantadas a respeito do peso relativo assumido por cada uma das matrizes, seus conceitos e obras de maior impacto, bem como e relação entre teoria e criação.

Palavras-chave: Música brasileira; Música eletroacústica; Música concreta; Música eletrônica; Música de computador.

Theoretical frameworks of Brazilian Electroacoustic Music and the influence of historical matrices

Abstract: in this paper we discuss the influence of three historical trends of electroacoustic music - musique concrète, elektronische Musik and Computer Music - in Brazilian electroacoustic music. A questionnaire was distributed among Brazilian composers in order to evaluate aspects ranging from composers output in the past five years to the impact of theoretical works and concepts related to the three historical trends in their own compositional thinking, among other topics. The answers were analyzed and a series of remarks and questions was raised concerning the relative influence of each historical trend among Brazilian electroacoustic composers and the relation between theory and invention.
\end{abstract}

KEYWORDS: Brazilian music; Electroacoustic music; Musique concrète; Elektronische musik; Computer music.

\section{Introdução}

Como já dissemos anteriormente, nossa investigação partiu de uma motivação prosaica. ${ }^{1}$ Confrontados com a exiguidade de textos teóricos em português para dar suporte a nossa atividade de ensino de graduação e pós-graduação no setor de música eletroacústica, perguntávamo-nos quais trabalhos deveríamos traduzir. Muitos dos textos fundamentais do gênero permaneciam à época, 2008, editados apenas em suas línguas originais, com poucas traduções para o português ou mesmo o inglês, no caso das publicações francesas e germânicas. Esta limitação enseja, a nosso ver, uma formação excessivamente dependente da interpretação dos textos fundamentais por parte do docente responsável pelas diversas disciplinas do setor, o que poderia suscitar uma orientação esteticamente limitada ou mesmo tendenciosa, incompatível com o espírito de esclarecimento e abertura que deve caracterizar o ensino superior.

Resolvemos, em seguida, transformar esta inquietação num mote de pesquisa. E resolvemos formular uma hipótese inicial, supondo que as principais obras teóricas do gênero permaneceriam pouco conhecidas em nosso meio, devido à dificuldade de acesso às publicações ou à inexistência de traduções. Como consequência, a prática da música eletroacústica brasileira se caracterizaria, sobretudo, pelo contato direto do compositor com sua ferramenta de trabalho, que ele "descobre" ou "recria" sem o amparo de referenciais teóricos estabelecidos historicamente. Não se trata de apontar um dedo acusador para os colegas dizendo que "não leram isto nem aquilo”. Trata-se de indagar, a partir de nossa própria ex- 
periência - tivemos acesso a um gravador de fita magnética e a um sintetizador analógico antes de ler qualquer texto de Pierre Schaeffer ou Karlheinz Stockhausen -, quais as consequências desta conjectura para a música eletroacústica brasileira. Uma delas, críamos, seria a esparsa e ainda pouco influente produção teórica brasileira.

Tememos, porém, abrir excessivamente o escopo de nossa investigação e perder o foco. Para evitá-lo, buscamos refúgio em escolhas teóricas e metodológicas, que discutiremos em detalhe adiante. Em alguns momentos, hesitamos, crendo-nos despreparados para a empreitada. Em outros, as vicissitudes da vida nos afastaram da continuidade deste trabalho, atrasando-nos. Apanhamos de um parecerista anônimo, a serviço de uma agência de fomento, que considerou nossa fundamentação teórico-metodológica “um arremedo", o que nos desestimulou. Mas seguimos em frente e contamos com colaboradores valiosos ao longo do percurso, aos quais somos gratos. ${ }^{2}$

Da hipótese inicial, partimos para a elaboração de um questionário, que se encontra em anexo (https://www.academia.edu/8899888/Questionario_Matrizes_Historicas_da_ Musica_Eletroacustica), e o distribuímos à quase totalidade dos compositores brasileiros de música eletroacústica e alguns outros que tiveram contato com o gênero em diferentes momentos de suas carreiras, tal como conseguimos mapear em 2010. ${ }^{3}$ Sessenta e quatro compositores foram abordados e, destes, quarenta e cinco responderam a nosso chamado, o que corresponde a $70 \%$ do universo consultado. Estas respostas e a análise que delas decorre compõem o âmago e o principal interesse deste estudo. Antes de chegar lá, porém, cumpre-nos aprofundar a discussão acerca de nossa metodologia de trabalho e dos referenciais teóricos que ampararam nossa iniciativa.

\section{Aspectos metodológicos e teóricos}

Nossa investigação está fundamentalmente apoiada na memória e nos relatos dos compositores que praticam ou praticaram o gênero eletroacústico em algum momento de suas carreiras, e que foram abordados por meio de um questionário. Desta forma, elementos metodológicos de História Oral foram de grande utilidade para o processo de pesquisa. ${ }^{4}$ As respostas ao questionário foram tratadas anonimamente e serviram de subsídio para a criação de um quadro que não pretende focalizar o compositor especificamente, mas o conjunto dos compositores.

Grande parte de nossos esforços esteve, portanto, centrada na confecção e na aplicação do questionário, bem como na tabulação dos dados e na interpretação das respostas obtidas. Pretendíamos inicialmente que a fase de interpretação fosse complementada com a análise de obras específicas - teóricas e musicais - e entrevistas de esclarecimento que auxiliassem na ilustração de aspectos relevantes apontados no questionário. No entanto, o longo decurso de tempo entre o começo da investigação e o momento atual bem como as respostas numericamente satisfatórias e qualitativamente claras que obtivemos fizeram-nos dispensar esta etapa para a confecção deste estudo.

A hipótese inicial foi, portanto, testada à luz das informações obtidas, o que nos permitiu tecer considerações que conduzem a uma compreensão um pouco mais aprofundada da influência da produção teórica relacionada às principais matrizes históricas do campo Musique Concrète, Elektronische Musik, Computer Music - na música eletroacústica brasileira.

Um dos aspectos centrais de nossa fundamentação foi a adoção de duas categorias, denominadas referenciais teóricos e contribuições teóricas. ${ }^{5}$ 
Já nos referimos a referenciais teóricos como conjunto de conceitos que amparam, orientam ou dialogam com os compositores, auxiliando-os na criação das condições de possibilidade de suas poéticas particulares, estando assim ligados àquilo que classicamente se tem denominado de nível poiético. Nossa abordagem esteve inicialmente relacionada a dois paradigmas fundamentais envolvendo a poiesis: um relacionado às reflexões de Martin Heidegger e outro fundamentado em Jean Molino. ${ }^{6}$ Neste sentido, pensar a poiesis serviu como delimitador de fronteiras (ou mesmo como mitigador de limites) entre teoria, conceitos e eventuais recursos tecnológicos, por um lado, e o ato criativo-composicional, por outro. Assim, no momento da composição, haveria contato com conceitos que alimentam o ímpeto criativo. Além disso, o instrumental técnico e tecnológico e as motivações psicológicas e emotivas apresentam-se também como constituintes do nível poiético. Desta forma, os referenciais teóricos configuram-se como alimentadores da poiesis, embora não sejam os únicos motivadores deste processo. Os referenciais seriam, então, alguns dos causadores da obra de arte, que, articulados pelo ímpeto criativo individual, convertem-se em música.

Na verdade, mais que - ou além de - causadores, os referenciais teóricos são mediadores entre o compositor e o som. De fato, mesmo aquilo que chamamos de "ímpeto criativo individual”, longe de ser uma só instância ou um único golpe, é constituído de uma série, por vezes intermitente, de tentativas, experimentos e escolhas de proporções e consequências variáveis. Em suma, mais mediações, como ficará claro em seguida. Como qualquer mediação, estas não devem ser entendidas como um simples instrumento neutro, mas, ao contrário, apesar de comumente consideradas como algo similar a uma tenaz, uma pinça ou um braço mecânico que simplesmente estende o comprimento de nosso próprio braço, as mediações precisam ser pensadas como algo que "traduz" ou mesmo "filtra" aquilo que passa por elas. Do contrário, não há como compreender de que maneira chega a existir diferença entre, por exemplo, a música produzida por indivíduos de formação similar, porém criando em ambientes diferentes.

No fundo, não temos aqui nada além do que nos oferece nossa intuição mais básica ao observar qualquer fenômeno da esfera social, descrevendo por meio de uma espécie de meta-categoria - mediação - aquilo que vemos difusamente como elementos que possuíam maior significação no contexto de origem: a formação, as influências ou as preferências pessoais de um dado indivíduo. Por exemplo, quando se afirma que a música de algum compositor possui "harmonia francesa", "melodia italiana” e "forma alemã", reportando-se à formação que este recebera em algum lugar específico, está-se recuperando uma série de mediações que podem ser apresentadas numa rede onde participam fatores os mais heterogêneos e onde não há extremidades com elementos entre elas, mas apenas mediações. A dificuldade reside no fato de que frequentemente nos esquecemos dessa lógica de operação do mundo ao construirmos nossas explicações sobre ele, tendendo a considerar que as mediações podem ser apagadas e substituídas por algo que supostamente seria a coisa em si a que elas se referem. Da mesma maneira que uma obra de compositor brasileiro não é a própria música brasileira, nenhuma mediação ocupa o lugar de outra coisa, mas sim é parte (específica) daquela coisa a que, por vício de raciocínio, tentamos remetê-la. ${ }^{7}$

Na abertura do questionário "Matrizes Teóricas", há um breve texto que visa a informar os respondentes dos objetivos gerais e pressupostos que animaram a pesquisa. Nele aparece a noção central de contribuição teórica, então entendida "como conjunto de conceitos, sistemas de classificação, métodos de análise, ambientes de programação ou mesmo técnicas utilizadas na produção de obras musicais”. Esta definição foi confeccionada em função das especificidades de cada uma das três principais correntes estéticas considera- 
das enquanto trabalhávamos na elaboração do questionário. Nesse sentido, o conhecimento destas variadas contribuições auxiliaria na compreensão de objetos, fenômenos e processos característicos do campo investigado. Foi importante, portanto, diferenciar referenciais teóricos de contribuições teóricas. A primeira categoria se apresentaria como fonte conceitual, enquanto a segunda seria um conjunto heterogêneo de ferramentas a ser utilizado por compositores. Em decorrência, haveria uma relação de continuidade entre essas duas categorias, a primeira amparando a segunda, enquanto a utilização das ferramentas listadas na segunda categoria revelariam a influência da primeira.

Pode-se de fato observar certa diferença no que diz respeito àquilo que essas duas noções potencialmente abarcam e onde incidem na "vida da obra", passando por sua realização e sua recepção, mas tendo como ponto privilegiado o(s) momento(s) de sua gestação. Assim, é possível entender as contribuições teóricas como relativamente mais abrangentes diacronicamente, enquanto os referenciais teóricos, na medida em que são conceitos que amparam, dialogam e alimentam o ímpeto criativo, teriam maior alcance em termos da invenção artística, mesmo que sua presença tenda a se concentrar mais no que diz respeito ao momento da concepção da obra em que tomam parte, restringindo-se à "faísca criativa". No entanto, é difícil avaliar em termos investigativos o ganho real de sustentar essa diferenciação quando o nível de operação de referenciais ou contribuições é tão profundamente intercambiável, até mesmo no fazer de um único artista.

Se, como foi dito acima, no limite as próprias fronteiras entre aqueles elementos que podemos designar por "teoria, conceitos e recursos tecnológicos" e o conjunto de decisões, experimentos e contingências que designamos pelo termo geral de "ato criativo-composicional" são colocadas em xeque - e este nos parece o ponto principal aqui -, talvez seja mais produtivo encontrar uma forma de dar conta de sua presença no fazer composicional sem, no entanto, depender de sua diferenciação.

Desse modo, a noção de mediação permite operacionalizar ambas as noções como possibilitadores ativos da obra, sem importar sua diferença, e sem que se perca de vista, porém, seu papel concreto. No fundo, como dissemos ao discutir a noção geral de mediação, do ponto de vista do pesquisador, tratam-se de meta-categorias que servem de gancho para que possamos agarrar o fenômeno concreto da criação musical. Do ponto de vista do compositor, referem-se a cada elemento figurando como algo que fertiliza, direciona, molda e é moldado (filtra e é filtrado) a partir daquilo que já traz anteriormente e do que tem a oferecer segundo a sua perspectiva desde o momento em que este começa a pensar em uma obra. ${ }^{8}$

\section{Respostas ao questionário "Matrizes Teóricas"}

Num grupo cujo fator de coesão é algo tão específico como a música eletroacústica, é sempre interessante observar onde as subdivisões internas aparecem. Dito de outra forma, a questão que se impunha era onde traçar as fronteiras.

Uma das hipóteses mais comuns em termos de delimitação de grupos ao trabalhar diacronicamente é a do fator geracional. ${ }^{9}$ Partindo desse pressuposto, certas caraterísticas tenderiam a incidir predominantemente sobre faixas etárias específicas dentro do grupo maior. Conforme dissemos anteriormente, o critério de escolha dos compositores que responderiam a nosso questionário era o de produzir ou já haver produzido música eletroacústica em algum momento de sua carreira. Além disso, buscamos levantar especificamente qual o tipo de produção a que o compositor vem se dedicando nos últimos cinco anos, chegando à proporção abaixo: 


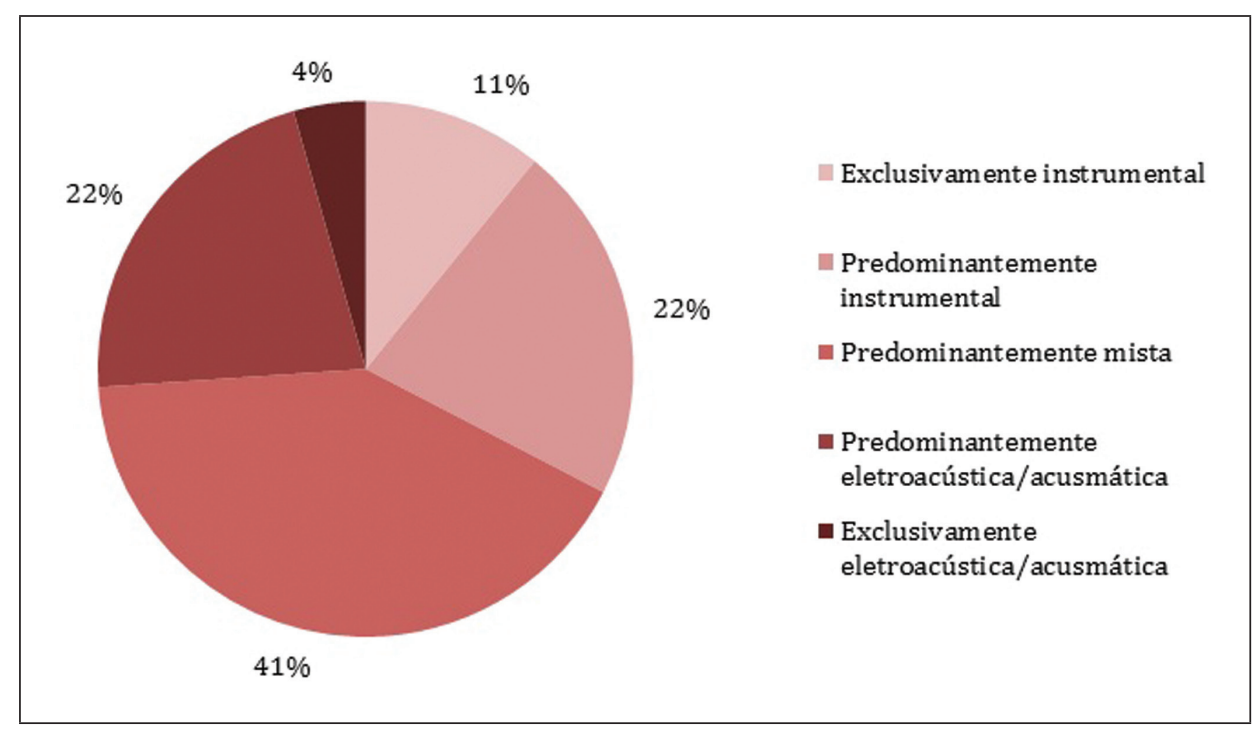

Gráfico 1: Produção recente.

Em termos etários, há desde aqueles que passam dos sessenta anos até compositores que estão por volta dos trinta, sendo que entre esses dois extremos está o grupo mais expressivo em termos numéricos. Em princípio, pensamos em dividir nossa amostra em faixas de dez anos: vinte a trinta, trinta a quarenta, quarenta a cinquenta e, por fim, um último grupo com mais de sessenta anos de idade. Esta última grande faixa se justificaria em termos da cronologia do próprio desenrolar da História das artes no século XX, pois aqueles que nasceram antes de uma determinada data assistiram aos desenvolvimentos da música eletroacústica ao longo do período a partir de perspectivas relativamente similares, ${ }^{10}$ algo que, de certo modo, foi reforçado pelas respostas dadas pelos indivíduos aí enquadrados.

Segundo nos parece, os compositores acima de sessenta anos em geral guardam uma relação mais próxima à de pares com as figuras principais que ajudaram a moldar aquilo que temos considerado como as matrizes da música eletroacústica. Como observou um dos respondentes, o que ele próprio e alguns de seus colegas fizeram foi tentar, "muito precariamente, [...] uma música feita em fitas, [...] com gravadores comuns, fita durex, aquela precariedade!” Assim, pode-se considerar o nascimento da música eletroacústica no Brasil como resultado de experiências pessoais, de tentativas realizadas um pouco com base na curiosidade de criar a partir de ideias que "estavam no ar" na época - e que esses compositores poderiam talvez chegar a ver como tão suas quanto de qualquer outro compositor então atuante. Isso é algo que se reforça levando-se em consideração que alguns destes compositores chegaram a trabalhar em estúdios internacionais junto a personagens centrais no desenvolvimento da música eletroacústica.

Em posição oposta, temos a geração de compositores mais jovens. Criar outra grande faixa abaixo dos quarenta anos foi de certo modo uma decisão prática em vista de haver apenas um respondente com menos de trinta anos, tomando-se por base ano de 2013, quando efetuamos a análise das respostas. Isto é algo em si já significativo, mas que também está relacionado ao fato de que nossa lista inicial foi criada a partir de compositores que participaram de Bienais de Música Brasileira Contemporânea, algo em geral mais raramente alcançado antes dos trinta anos, além daqueles listados no site MUSICON CDMC/UNICAMP e os associados à Sociedade Brasileira de Música Eletroacústica (SBME), que parecem não absorver o contingente de compositores mais novos de forma significativa. ${ }^{11}$ Entretanto, a forma de se relacionar com o conteúdo que serve de objeto ao questionário reforçou, mais 
uma vez, essa perspectiva. Embora possivelmente haja diferenças importantes no modo de adesão à ideia mais geral de uma música de concerto entre os compositores de trinta a quarenta anos e aqueles abaixo dos trinta, a relação com as matrizes parece bastante similar, e eis aí o porquê de falarmos numa posição até certo ponto oposta àquela faixa de idades mais avançadas. A resposta de um dos compositores pertencentes ao grupo mais jovem é bastante elucidativa neste sentido: ao incluir outras formas de acesso ao legado de cada uma das matrizes, fez questão de acrescentar às opções "seminários", "programas radiofônicos", "documentários" etc. a indicação pura e simples "Internet".

Não que aqui estejamos necessariamente argumentando em favor da Internet como meio privilegiado de alcançar o conhecimento acumulado, mas é importante ter em conta de que se trata de forma de acesso menos "formal" a conteúdos que provavelmente foram produzidos por pessoas de idade muito próxima à dessa geração e animadas por preocupações similares. ${ }^{12}$ Ao que nos parece, figuras como Pierre Schaeffer, Karlheinz Stockhausen ou Max Matthews são muito mais presentes para as outras faixas etárias do que para os jovens, que parecem guardar com elas o mesmo tipo de relação que se tem com "clássicos".

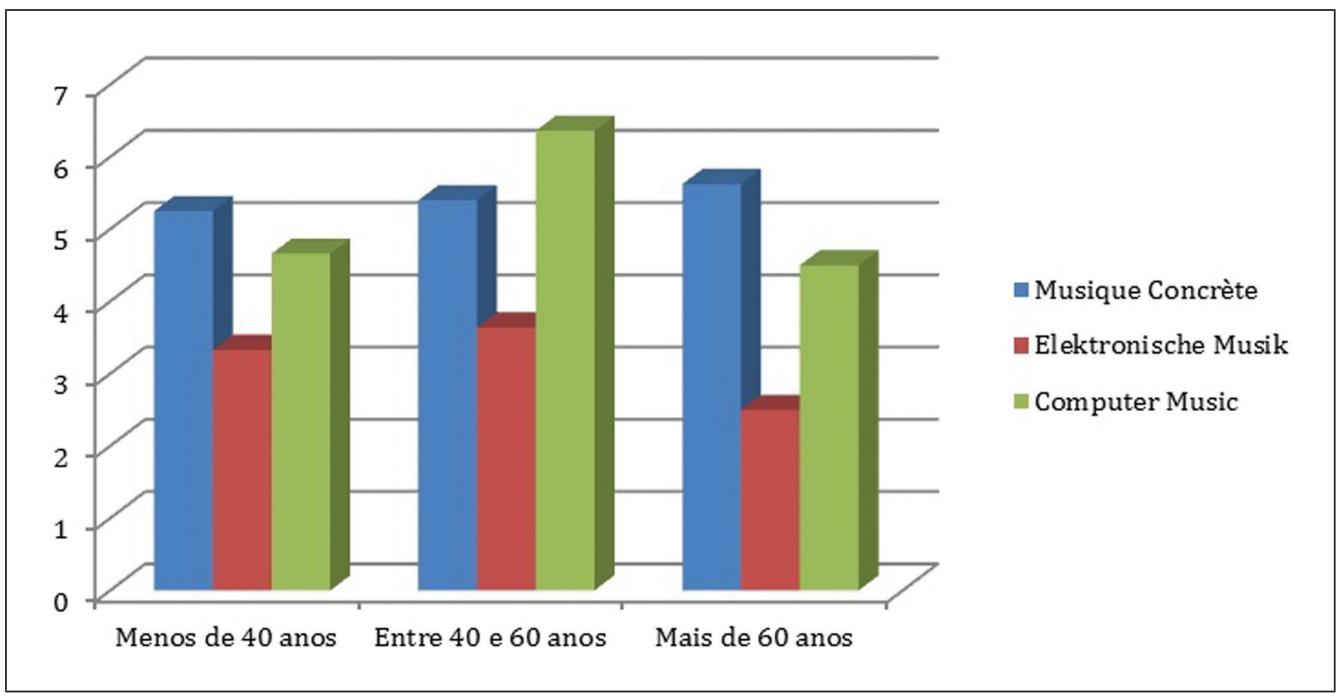

Gráfico 2: Média de livros lidos (segundo faixa etária, em números absolutos).

Como se pode ver no Gráfico 2 (acima), com exceção da vantagem expressiva da Computer Music junto aos respondentes entre quarenta e sessenta anos de idade e do alcance menor da Elektronische Musik entre a geração mais velha, as leituras estão distribuídas entre as faixas etárias de maneira significativamente homogênea, trazendo à tona uma questão fundamental no desenvolvimento da presente pesquisa: a maneira como se estabelece a relação entre criação musical eletroacústica e conhecimento teórico. Para além do que assinalamos acima, não foi possível enxergar qualquer padrão ou diferença geracional clara. Isso pode estar ligado, em parte, a características específicas do grupo com que trabalhamos, visto que não só se trata de um universo relativamente pequeno em termos absolutos - o que dificulta o traçado de generalizações de maior alcance - como também porque as duas faixas etárias do meio, quarenta-cinquenta e cinquenta-sessenta, representam algo próximo a 50\% do total, dominando numericamente a população de respondentes - algo que também já configura informação relevante. Além disso, a grande maioria atua como compositor há mais de vinte anos e 83\% deles estão vinculados de alguma forma à universidade, o que revela ainda mais homogeneidade na amostra. 


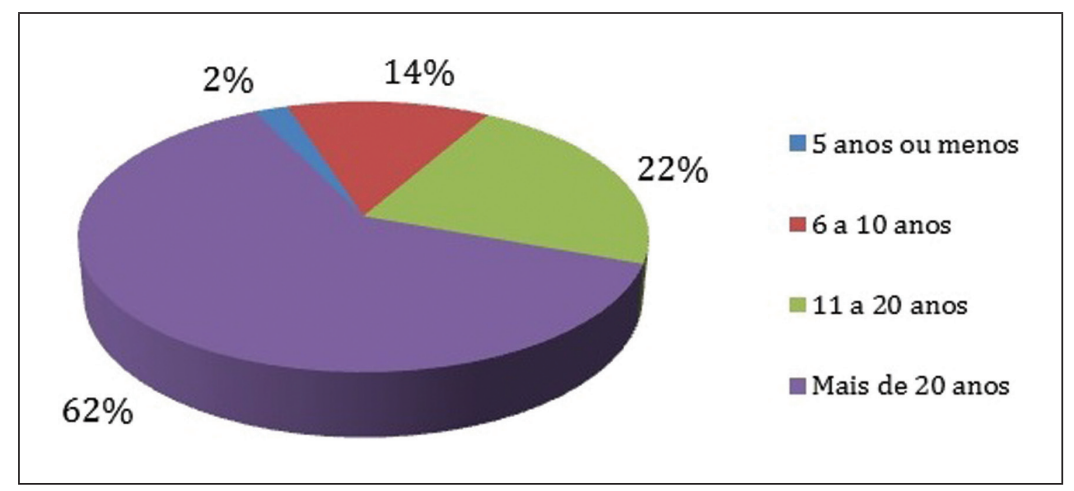

Gráfico 3: Tempo de atuação como compositor.

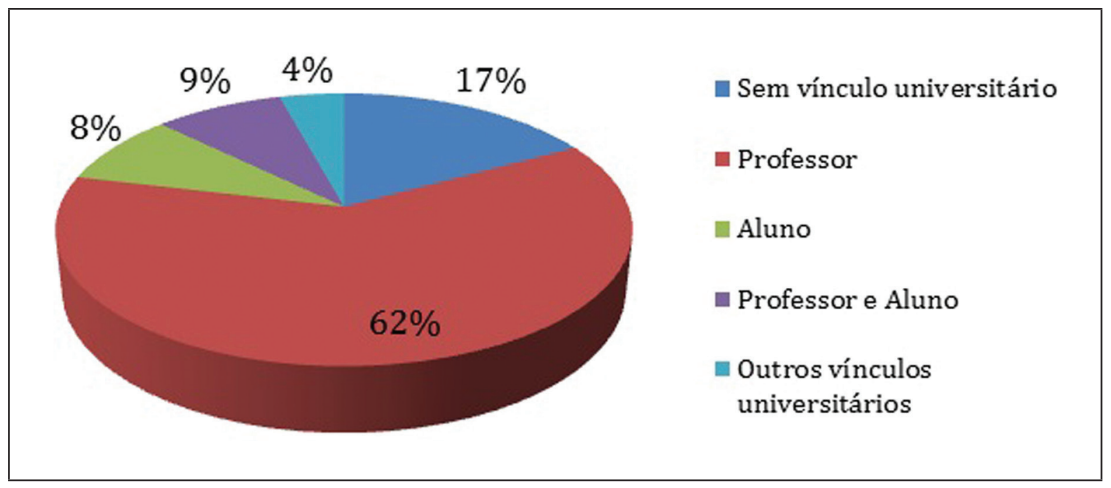

Gráfico 4: Vínculo Universitário.

Mas a questão é que, contrariamente ao que havíamos suposto em nossa hipótese inicial, a própria criação no campo da música eletroacústica parece estar especialmente ancorada no conhecimento teórico, e eis aí outra razão porque haveria tanta homogeneidade na amostra.

Após uma primeira leitura das respostas ao questionário, pareceu-nos possível detectar uma diminuição da influência da Elektronische Musik junto às gerações mais jovens, ao mesmo tempo em que a Computer Music cresceria em importância, permanecendo a Musique Concrète mais ou menos estável em termos de influência. Malgrado nossa inclinação a, seguindo a hipótese geracional clássica, enxergar essa variação de influência entre as correntes segundo as faixas etárias dos respondentes, como dissemos, a tabulação e avaliação cuidadosa das respostas obtidas se mostrou refratária ao estabelecimento de qualquer padrão geracional mais específico.

Assim, essa homogeneidade é já significativa. Como dissemos, dentre os compositores brasileiros que produzem ou produziram música eletroacústica que pudemos mapear, cerca de 70\% responderam ao questionário, o que oferece um número expressivo em termos relativos. Desse modo, apesar de todas as diferenças de origem, faixa etária e mesmo de formação, aquilo que esses compositores leram e o que os marcou, especialmente no que tange ao que estamos entendendo aqui por "matrizes da música eletroacústica” teve um alcance bastante similar.

Mesmo levando em conta que alguns dos respondentes sugeriram que fossem acrescentados outros campos ligados à música eletroacústica que teriam importância em seu pensamento composicional, sendo a noção de soundscape a mais mencionada, estes podem ser entendidos como passos posteriores do desenvolvimento das correntes que resultaram no que chamamos hoje de música eletroacústica. ${ }^{13}$ Além disso - e mais importante -, apesar das observações sugerindo mais uma ou outra possível matriz, nenhum dos respondentes colocou em questão a pertinência daquelas três matrizes em que baseamos nosso questio- 
nário, o que de certo modo confirma sua importância para se pensar o desenvolvimento das formas musicais que aqui nos ocupam.

O acesso a publicações formais pode significar um valor em si para as gerações formadas antes do advento da Internet como experiência cotidiana, quando o acesso ao conhecimento se dava prioritariamente por livros e, em menor grau, por documentários e programas de televisão ou rádio. Nosso próprio questionário pode ser acusado disso, dada a ênfase colocada sobre livros e textos, deixando apenas uma questão ao fim de cada seção para "outras formas de acesso ao legado teórico". Isso foi inclusive observado por um dos respondentes. ${ }^{14}$ Porém, como dissemos na primeira seção deste estudo, as questões que animavam a elaboração inicial da pesquisa justificam esse olhar específico, preocupados que estávamos com o que traduzir para nosso idioma dentre aquilo que integrava o corpo teórico das matrizes históricas. Ainda assim, dada a ligação dos autores do presente artigo com a música eletroacústica, pode-se insistir que essa própria preocupação é um sinal eloquente da atenção maior que é dispensada à leitura de publicações formais. Longe de ser um problema neste momento, temos com isso a confirmação de um dos aspectos ligados à própria hipótese que estávamos procurando testar: o valor dado a obras teóricas publicadas como forma de acesso ao conhecimento por parte dos envolvidos com música eletroacústica no Brasil. Além disso, como pudemos apurar, a grande maioria dos respondentes está ligada à universidade. De certo modo, isso ajuda também a explicar porque o acesso ao conhecimento por meio da leitura é maior, visto que, da maneira como o ensino é organizado, aulas expositivas tendem a ser acompanhadas da recomendação de leituras, tornando o lidar com livros uma verdadeira necessidade profissional. Além disso, um pouco como desdobramento de procedimentos do método científico, pode existir certa ênfase no acesso à informação de primeira mão ou que ao menos possa ser verificada: a quantidade expressiva de respondentes - aproximadamente 92\% - que assinalou ter lido ao menos uma das obras em sua versão traduzida e em sua língua original parece-nos indicar uma preocupação com o acesso ao texto em primeira mão, de modo a evitar as interpretações sobrepostas de tradutor e leitor.

Outras considerações interessantes a fazer estão ligadas à relação geral entre o conhecimento do legado teórico das três matrizes e a influência exercida por elas sobre a produção desses compositores. Como se pode perceber nos dois gráficos abaixo, a Elektronische Musik ocupa uma posição curiosa, especialmente se lembrarmos que, simultaneamente, a Computer Music teve um alcance muito grande em termos de leituras das obras ligadas a ela - algo que vimos no Gráfico $2 .^{15}$

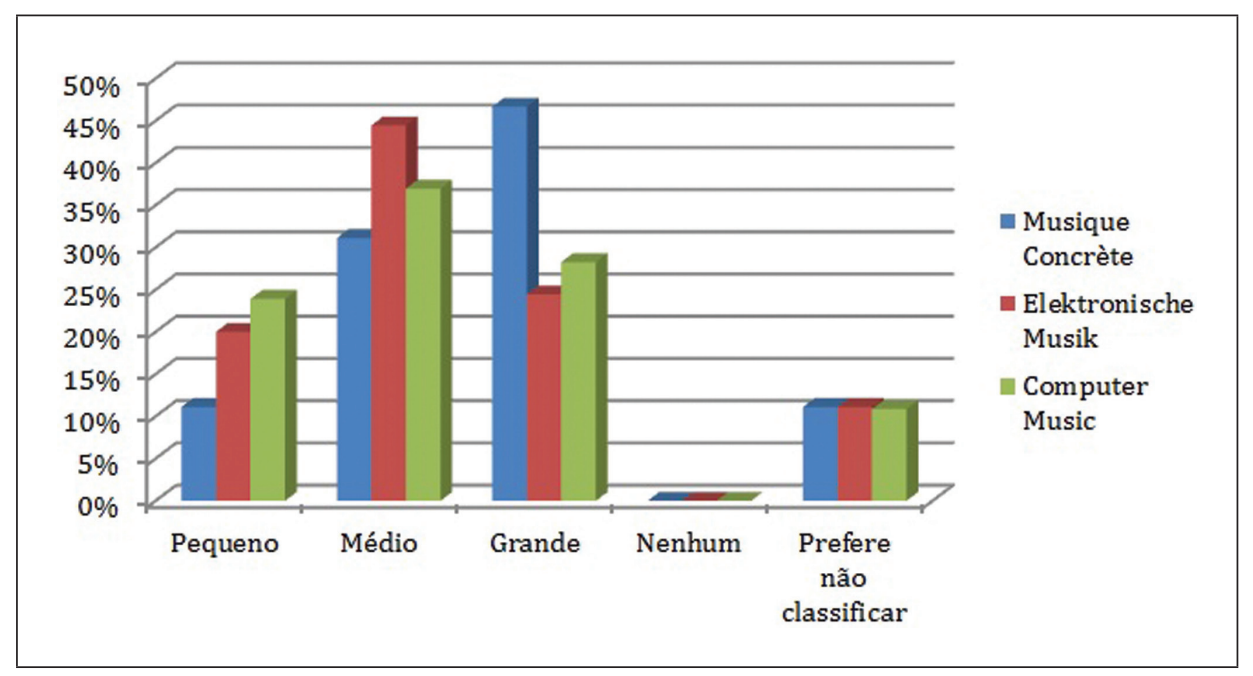

Gráfico 5: Conhecimento do legado teórico. 


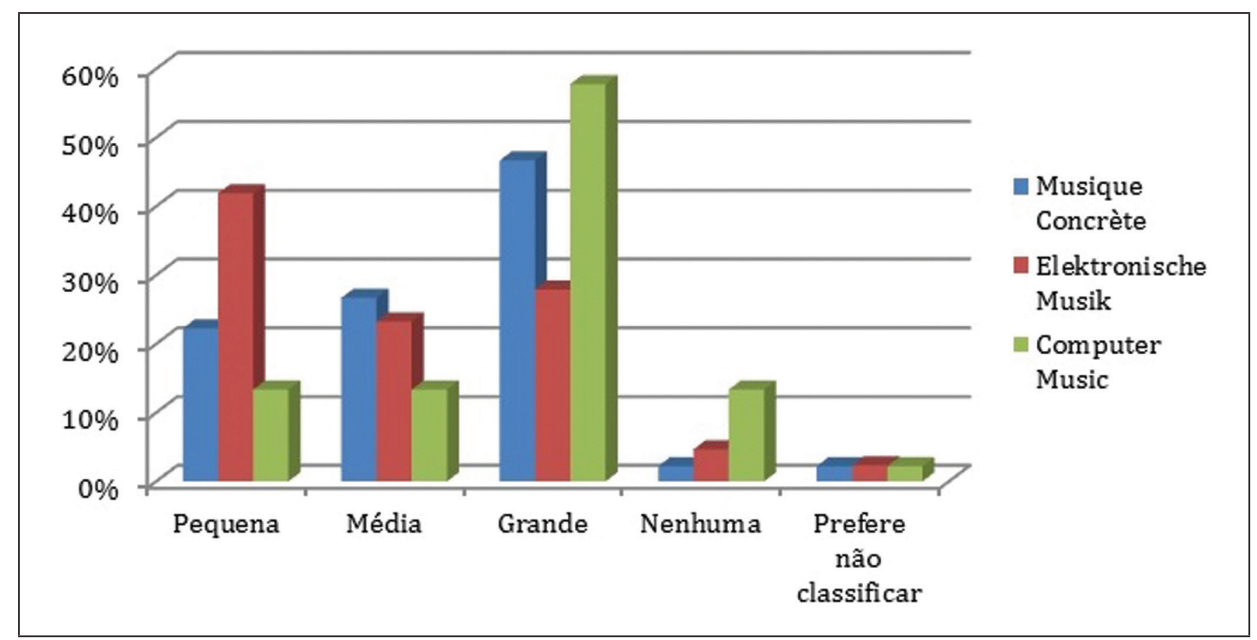

Gráfico 6: Influência sobre a produção composicional.

Caso se queira olhar por outra perspectiva o acesso aos livros mais significativos que formam o legado das três matrizes, pode-se verificar simplesmente quais foram as obras mais mencionadas:

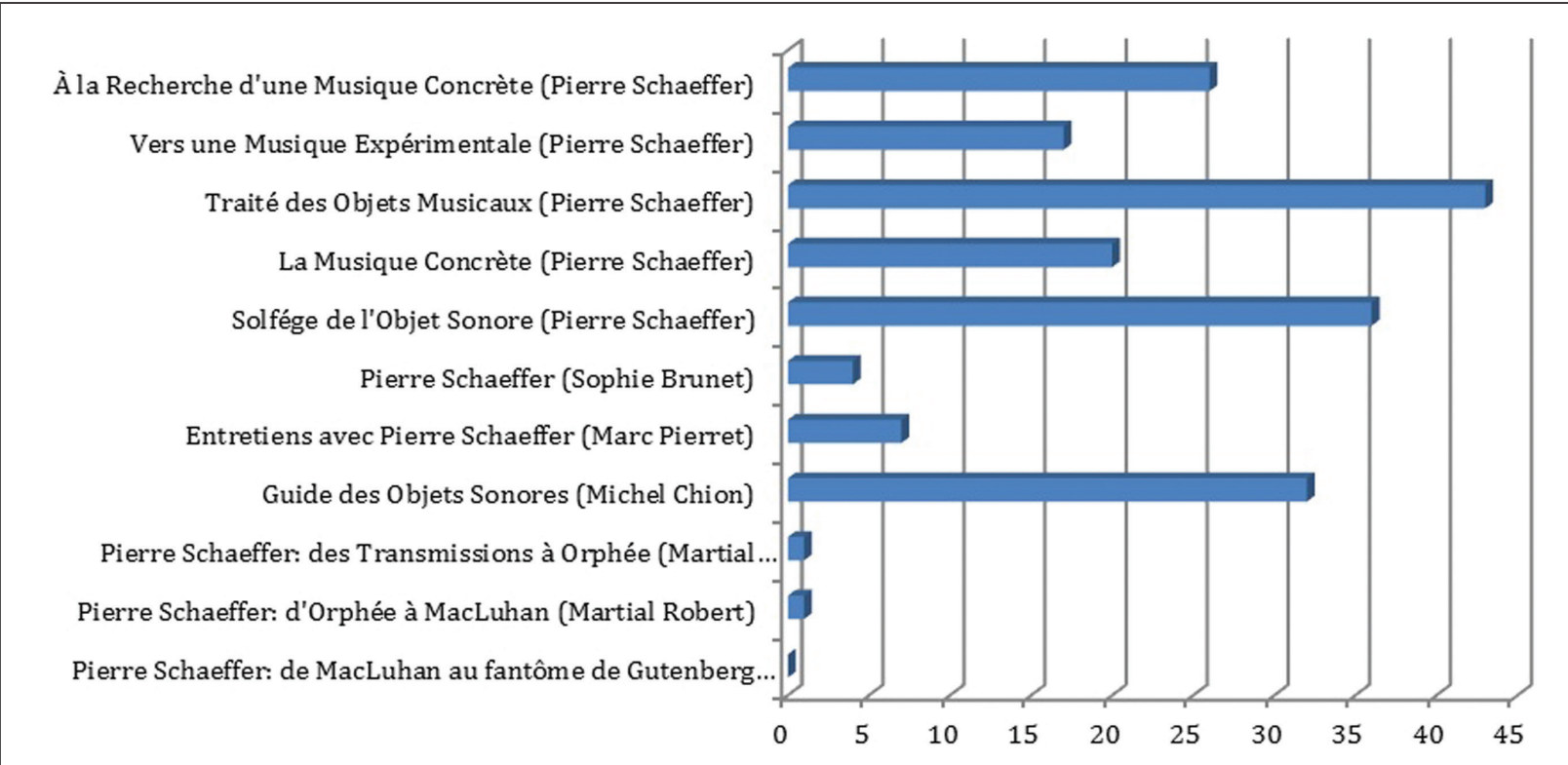

Gráfico 7: Acesso à Literatura sobre Computer Concrète.

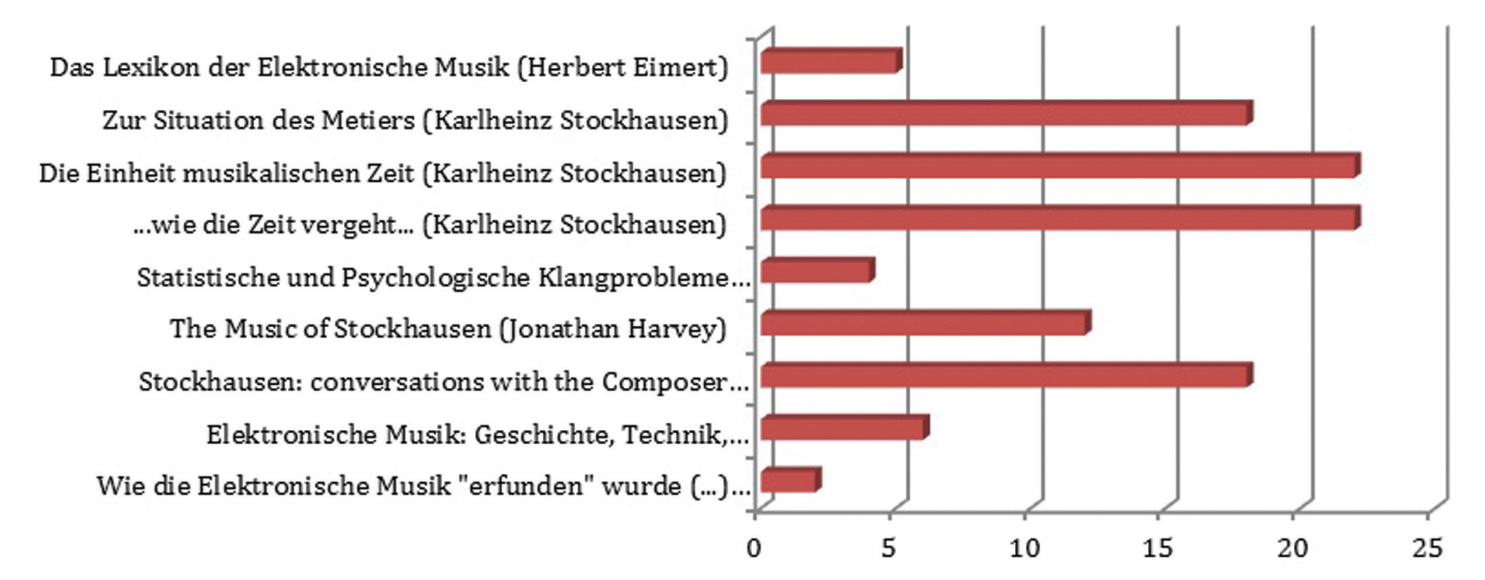

Gráfico 8: Acesso à Literatura sobre Elektronische Music. 


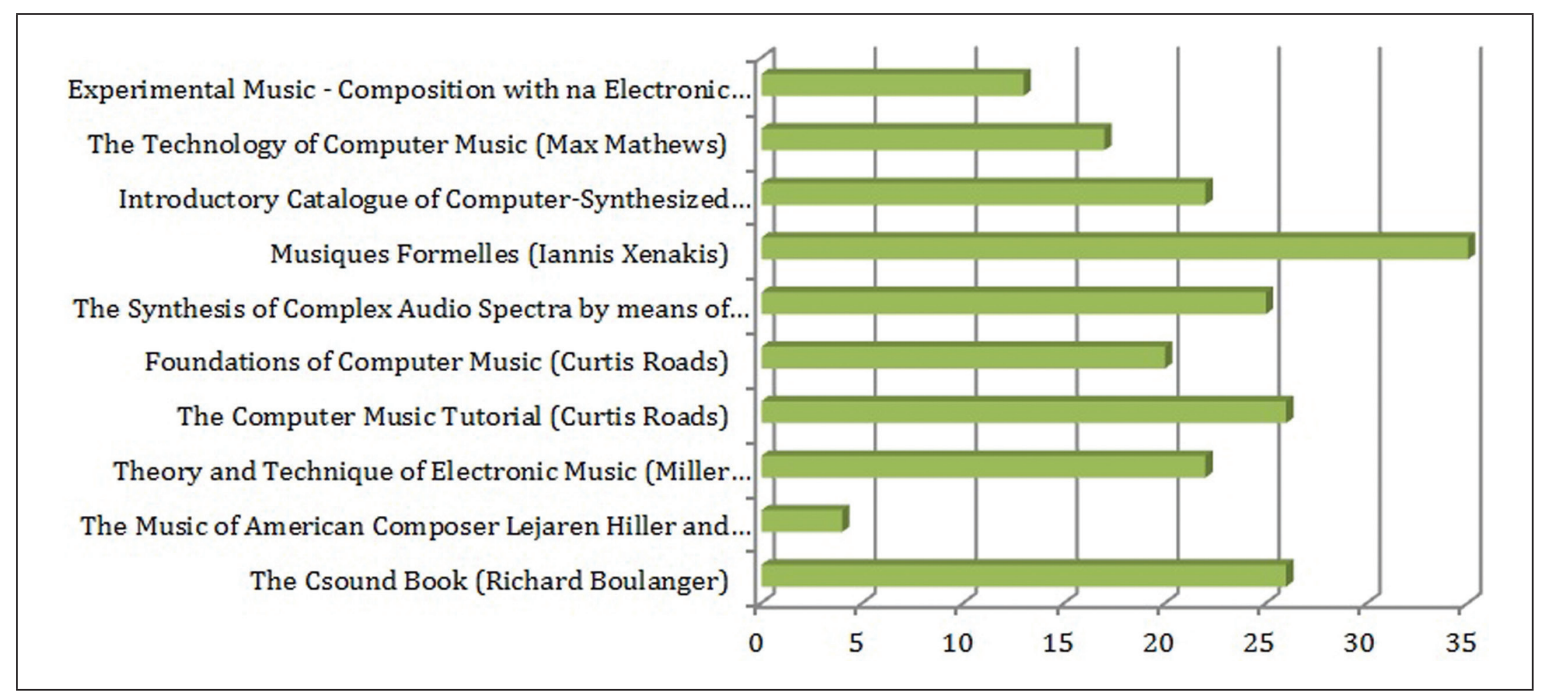

Gráfico 9: Acesso à Literatura sobre Computer Music.

Vale destacar que, além das obras mencionadas acima, elencadas no questionário original, outras mereceram algumas indicações espontâneas, como Le Son, de Michel Chion, The Language of Electroacoustic Music, editada por Simon Emmerson, Electronic and Computer Music, de Peter Manning, e On Sonic Art, de Trevor Wishart. De resto, nas poucas ocasiões em que algum dos respondentes fez questão de incluir uma obra no campo “Outras. Indicar:”, raras foram as repetições e o número de obras extras não nos pareceu particularmente significativo. ${ }^{16}$

Sendo o inglês a língua estrangeira mais amplamente disseminada entre o público brasileiro, não surpreende que o legado teórico da Computer Music, de origem predominantemente norte-americana, tenha tido maior alcance, especialmente junto à geração entre quarenta e sessenta anos (Gráfico 2) e que acompanhou de perto o desenvolvimento do computador pessoal, passo decisivo para a ampliação do acesso à produção de música eletroacústica. Voltaremos a isso, mas antes continuemos a observar os Gráficos 5 e 6. Aqui, não só vemos que a influência da Computer Music é comparativamente mais bem distribuída como, olhando a coluna referente a "grande conhecimento" no Gráfico 5, vemos que a Musique Concrète conta com uma vantagem expressiva em termos de compositores que afirmaram possuir um conhecimento profundo de seu legado, seguida então por Computer Music e Elektronische Musik. Provavelmente, mais uma vez o fator linguístico desempenha algum papel no caso, pois esta última matriz é a única das três em que a leitura de traduções é maior que a leitura de textos na língua original. Porém, a Elektronische Musik é, curiosamente, aquela que goza do maior conhecimento médio entre todas as faixas, com uma vantagem de cerca de dez pontos porcentuais em relação à segunda colocada.

Já em relação à Musique Concrète, talvez seja possível sentir um reflexo tardio da influência francesa que marcou por muito tempo a tradição intelectual brasileira. Algo que se confirmaria, então, se interpretássemos o Gráfico 5 a partir do Gráfico 6, onde vemos que, apesar de muito lida - contando com quase vinte pontos porcentuais de vantagem em relação à Computer Music entre aqueles que afirmaram ter um conhecimento profundo de seu legado -, ela fica cerca de quinze pontos percentuais abaixo desta em termos de influência.

Neste gráfico, torna-se visível também mais um traço da penetração da Elektronische Musik: aproximadamente 45\% dos respondentes afirmaram ter sofrido pequena influência desta corrente. No entanto, ao observarmos os conceitos mais significativos para a produção 
de nossos respondentes, vemos que as técnicas analógicas de síntese do som, um dos pilares da matriz em questão, figuram simplesmente entre os três mais citados, logo após sua contraparte digital e tendo em primeiro lugar a noção de Objeto sonoro:

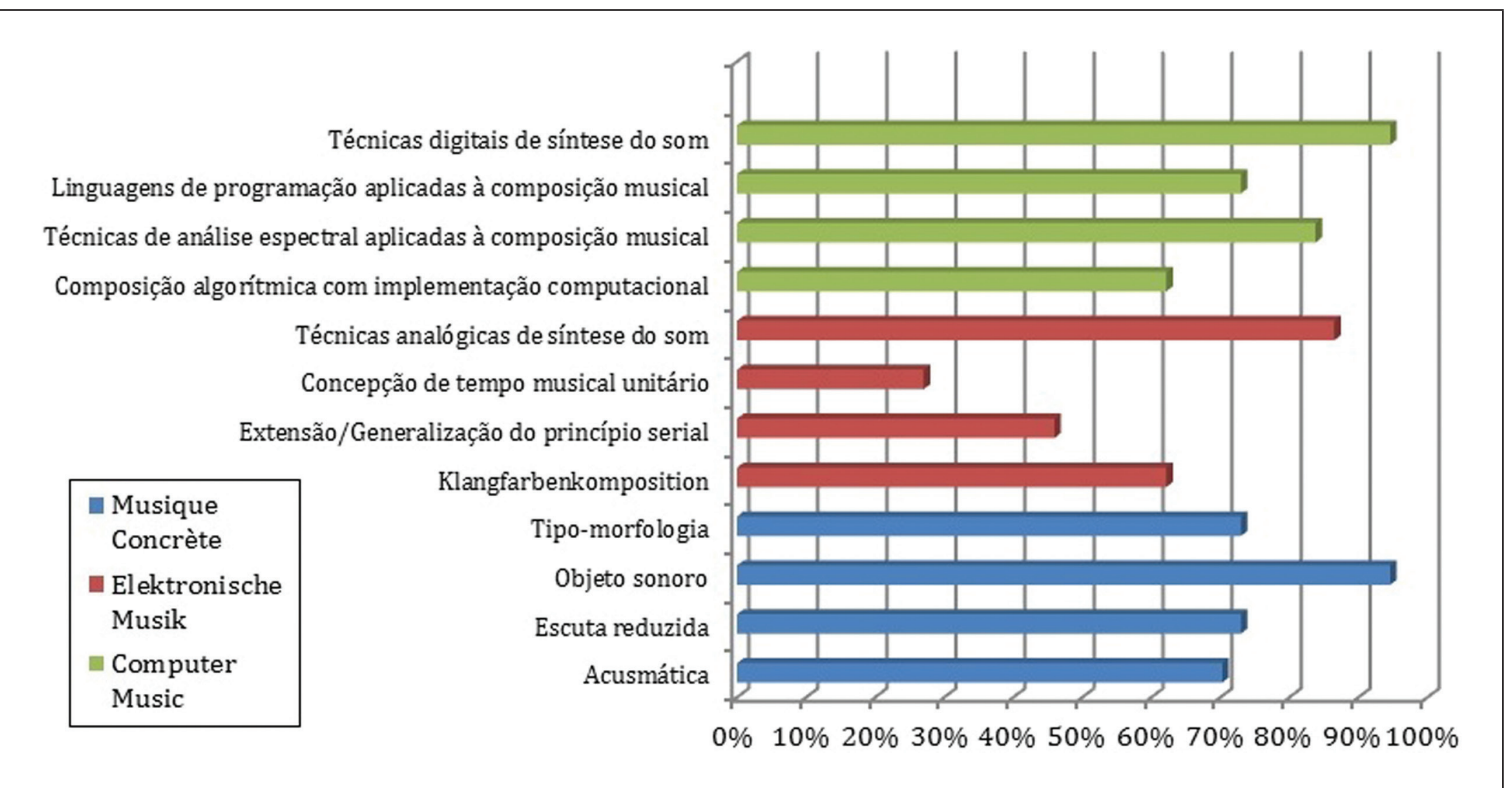

Gráfico 10: Conceitos e contribuições teóricas mais influentes.

Pode-se argumentar que a síntese do som, independentemente de sua modalidade analógica ou digital, seja uma ideia tão ampla que cada um pode fazer dela o que quiser, tomando-a muito mais como uma simples ferramenta (sem História?) do que buscando referenciá-la às próprias matrizes em que se enraízam. O fato é que isso importa relativamente pouco aqui, pois é justamente do uso feito das ideias que surgiram dessas matrizes que tratamos, interessados em tentar perceber como este uso vem fertilizando a música eletroacústica produzida entre nós. Além disso, o fato do grupo de respondentes ser predominantemente de compositores de música mista também pode desempenhar um papel significativo, pois técnicas de síntese sonora talvez sejam justamente algumas das que mais facilmente transitam entre os meios eletroacústicos e instrumentais. Já a noção de objeto sonoro quase se confunde com a noção de música eletroacústica, tendo sido apropriada mesmo por críticos ferrenhos da vertente concreta, de onde se origina, além de projetar sua influência para além do campo eletroacústico.

Um último tema a ser levantado é o próprio lugar assumido pelo computador pessoal na música eletroacústica contemporânea. Algo que no passado poderia ser realizado apenas em estúdios ligados a grandes instituições foi se tornando aos poucos acessível a qualquer compositor interessado no tema, podendo mesmo ser carregado em um computador portátil. Assim, é compreensível que o campo ligado à Computer Music seja uma porta de entrada privilegiada. Algo que se reforça, como já observamos, devido à acessibilidade linguística - afinal, não só o inglês é a língua mais lida como a proporção de conteúdo disponível em inglês na Internet é significativamente maior que nas outras línguas em questão aqui. Porém, é preciso ter em mente o que se faz com o computador e não confundir usar um computador com Computer Music. ${ }^{17}$ Neste sentido, cremos que o questionário que apresentamos permite um mapeamento mais refinado das influências que ajudam a dar forma à música eletroacústica brasileira. 


\section{Considerações finais}

Com esta investigação, constatamos que nossa hipótese inicial foi refutada, havendo indicações claras de que a música eletroacústica brasileira é não só fortemente influenciada pelas matrizes teóricas históricas, como apresenta um alto grau de exposição aos textos fundamentais da Musique Concrète, Elektronische Musik e Computer Music, de acordo com o que informaram os compositores em resposta ao questionário. Entra em xeque, portanto, a suposição de que se faria necessária a tradução de textos fundamentais para nossa língua, tendo em vista a verificação de que textos traduzidos e textos originais foram cotejados em ao menos uma ocasião por cerca de $92 \%$ dos respondentes. Também acreditamos que, em consequência, fica em dúvida outra decorrência de nossa conjectura inicial, a de que a produção teórica brasileira seria esparsa e ainda pouco influente em nosso meio.

Além desta questão, acreditamos que caberia investigar, num passo seguinte, a forma como se deu a formação destes compositores; quem foram seus professores; quem foram os disseminadores da música eletroacústica no Brasil; em que centros estão baseados; quais os espaços de divulgação desta música no país; e, principalmente, quais foram as referências posteriores que informaram o pensamento composicional de nossos respondentes, dentre as quais poderia figurar a produção teórica autóctone, seja ela esparsa ou não.

Todavia, acreditamos ter-nos dedicado a observar o conjunto de compositores por tempo demasiado. A menos que a própria comunidade sinta a necessidade no prosseguimento desta autópsia, nossa curiosidade vem se deslocando para a investigação da trajetória de figuras particulares. Talvez falando do indivíduo possamos, paradoxalmente (num esforço metonímico?), traçar um quadro que abarca toda uma geração e, assim, pelo esforço concentrado de narrar uma história singular, possamos tecer um panorama mais abrangente que diz respeito a todo o grupo.

Todos conhecemos ao menos algumas das muitas lacunas existentes na História da música brasileira. Acreditamos que apenas como resultado do esforço acumulado de diversas pesquisas - algo que vem crescendo nos últimos anos entre as pós-graduações do país, mas que ainda levará tempo para tomar corpo - é que será possível entender a posição que nossa produção ocupa, tanto dentro do país quanto em relação ao que se vem fazendo internacionalmente.

\section{Notas}

1 Este estudo encerra uma atividade de pesquisa cujas etapas de elaboração foram objeto de publicações anteriores. Para a fase inicial, ver: VELLOSO, Rodrigo Cicchelli et alii. Referenciais Teóricos da Música Eletroacústica Brasileira Contemporânea: apontamentos iniciais. In: COLÓQUIO DE PESQUISA DA PÓS-GRADUAÇÃO, 8., 2008, Rio de Janeiro. Anais. Rio de Janeiro: PPGM/EM/UFRJ, no prelo. Para as considerações em torno do questionário distribuído a compositores, ver: VELLOSO, Rodrigo Cicchelli et alii. Referenciais Teóricos da Música Eletroacústica Brasileira Contemporânea: acerca de um questionário. In: CONGRESSO DA ASSOCIAÇÃO NACIONAL DE PESQUISA E PÓS-GRADUAÇÃO EM MÚSICA, XIX., 2009, Curitiba. Anais. Curitiba: ANPPOM, 2009, p. 501-504. Não repetiremos aqui tudo o que foi dito nos textos anteriores, mas faz-se necessário recapitular criticamente o percurso realizado à luz do tempo decorrido entre as intenções iniciais e a análise dos dados obtidos.

2 Gostaríamos de agradecer a Gustavo Campos Guerreiro, Gustavo Emmanuel Alves Vianna de Lyra, José Rafael Valle Gomes da Costa e Paulo Roberto de Sousa Dantas, ex-alunos que participaram de nosso grupo de pesquisa entre 2008 e 2010 e com quem assinamos os trabalhos anteriores. Somos igualmente gratos às contribuições e comentários enriquecedores de Samuel Araújo, Stella Sabbatini e Tiago Dantas, que nos auxiliaram em diferentes momentos desta jornada. Quaisquer erros ou omissões do presente trabalho são, no entanto, de nossa única responsabilidade.

3 Neste mapeamento, consultamos a relação de compositores com obras apresentadas nas Bienais de Música Brasileira Contemporânea, a base de dados do MUSICON CDMC/Unicamp e a página da Sociedade Brasileira de Música Eletroacústica (SBME) na internet, além de fontes bibliográficas que tratam da música brasileira con- 
temporânea: CACCIATORE, O. G.. (2005). Dicionário Biográfico de Música Erudita Brasileira. Rio de Janeiro: Forense; MARIZ, V.. (2000). História da Música no Brasil. $5^{\text {a }}$ edição. Rio de Janeiro: Nova Fronteira; NEVES, J. M.. (1981). Música Contemporânea Brasileira. São Paulo: Ricordi.

4 Apoiamos este aspecto de nossa metodologia em MEIHY, J. C. S. B.. (2005). Manual de História Oral. $5^{\mathrm{a}}$ edição. São Paulo: Editora Loyola.

5 Ver: VELLOSO, Rodrigo Cicchelli et alii. Referenciais Teóricos da Música Eletroacústica Brasileira Contempo-rânea: acerca de um questionário. In: CONGRESSO DA ASSOCIAÇÃO NACIONAL DE PESQUISA E PÓS-GRADUAÇÃO EM MÚSICA, XIX., 2009, Curitiba. Anais. Curitiba: ANPPOM, 2009, p. 501-504.

${ }^{6}$ Referimo-nos aqui ao primeiro dos três níveis da tripartição de Jean Molino, utilizada como base da análise semiológica de Jean-Jacques Nattiez. (NATTIEZ, 1975). Uma aplicação recente de um modelo semiológico de análise calcado em Molino/Nattiez pode ser encontrada em (SPOLADORE, 2008).

7 Para uma discussão aprofundada do tema da mediação, ver HENNION, 2007: segunda parte e LATOUR, 2007: 91ss.

${ }^{8}$ A noção de mediação deve muito a Antoine Hennion e Bruno Latour, entre outros autores trabalhando próximo à Sociologia da Tradução (ou Actor-Network Theory, como costuma ser denominada no mundo anglófono). Porém, para que fique claro como estamos nos apropriando das contribuições desses autores, ressaltamos que um passo importante foi dado no trabalho - anterior ao de Hennion - de Ann Swidler e sua noção de cultura como caixa de ferramentas. Temos como ponto de partida aqui a noção (pragmatista, diga-se de passagem) de que os atores recorrem a categorias, conceitos, ideias, elementos musicais, imagens ou o que mais estiver presente em seu ambiente cultural como ferramentas, que podem ser usadas de maneira mais ou menos convencional, mas que sempre fazem com que se realize algo de acordo com as possibilidades e características que a própria ferramenta previamente traz. Não deveria haver qualquer dúvida para os leitores habituados a esta perspectiva, mas ainda assim talvez seja importante frisar que não estamos naturalizando quaisquer possíveis características prévias que alguma dessas ferramentas possa ter. O que queremos dizer com "possibilidades e características que a própria ferramenta previamente traz" é que elas não passam daquilo que sua própria História sedimentou nelas. É precisamente por isso que o uso que se faz de uma ferramenta é em maior ou menor medida convencional. Ainda que possam desconhecer um objeto e para que ele serve, os atores têm conhecimento prévio do mundo - formando mais uma série infinita de mediações - em quantidade suficiente para intuir ou deduzir usos para aquele objeto. Ver SWIDLER, 1986, HENNION, 2007, LATOUR, 2007.

9 A noção de geração tem uma longa, embora talvez discreta, história, partindo pelo menos de Auguste Comte e passando por Karl Mannheim (1952), Paul Ricoeur (2003, com as noções de “próximos”, “contemporâneos” etc.) até chegar a Pierre Bourdieu (1979, 1998), entre outros. Aqui, usamos a noção de maneira um tanto livre, apenas para designar grupos de pessoas de idade próxima e que partilham de aspirações e preferências significativas no que diz respeito ao tema em questão.

${ }^{10}$ Como já observava Mannheim (1952), fatos históricos significativos costumam marcar de tal modo a experiência de mundo dos indivíduos que acabam sendo determinantes de sua geração.

11 Para um levantamento recente e completo de compositores presentes nas Bienais de Música Brasileira Contemporânea, ver o programa da última edição do evento em: SILVA, F. (ed.). XX Bienal de Música Brasileira Contemporânea. Rio de Janeiro: Funarte, 2013.; para o MUSICON, ver http://www.unicamp.br/ciddic/compositores.html (último acesso em 26/11/2013); para o site da SBME, ver: http://www.sbme.com.br/associados.htm (último acesso em 26/11/2013).

12 A Internet vem progressivamente incorporando a transcrição de publicações formais em seu seio, e alguns dos títulos mencionados ao longo do questionário podem ser encontrados em sites de acesso limitado ou livre.

13 Alguns respondentes mencionaram publicações de François Bayle, Simon Emmerson, Trevor Wishart e outros, claramente relacionadas a momentos posteriores aos das matrizes, e delas tributárias. Um dos respondentes mencionou sofrer influência do Studio di Folonogia Musicale de Milão, concedendo, no entanto, tratar-se o trabalho deste estúdio de resposta ao primeiro impulso. Um único respondente menciona ser influenciado por práticas que em sua opinião não teriam relação com as matrizes adotadas no questionário, tais como "criação de obras radiofônicas, criação sonora com narrativa literária, criação musical em obra áudio-visual, criação musical em teatro, concepção de situações sonoras em ambientes, design sonoro em domínio amplo, improvisação musical, trabalhos sobre gesto musical a partir de analises de idéias musicais e princípios musicais." No entanto, é possível localizar e correlacionar estas práticas às matrizes adotadas, havendo numerosos exemplos de sua ocorrência no seio das próprias matrizes.

${ }^{14}$ Este respondente questionou: "Não entendi por que uma conversa serve, mas uma audição de obras não serve como contribuição teórica. A teoria não pode resultar de uma elaboração durante ou pós-escuta, ou precisa passar pelo filtro da palavra?” A estratégia adotada nesta investigação procurou excluir a possibilidade da obra musical ser, em si, teoria. Conforme já dissemos em outro lugar: "A partir dessas reflexões, torna-se possível iniciar um exercício que nos ajuda a definir o que é referencial teórico pelo que não é referencial teórico. A obra de arte em si é o primeiro elemento a ser retirado desse campo de possibilidades, embora, logicamente, seja admissível apropriar-se de uma obra sob uma perspectiva analítica e extrair dela elementos conceituais e técnicos, que serviriam como suportes teóricos.” Ver: VELLOSO, Rodrigo Cicchelli et alii. (2009), p. 502

15 Para fins de visualização nos Gráficos 5 e 6, optamos por aglutinar os dois níveis extremos da classificação em "Pequeno" e "Grande". Assim, conhecimento "superficial" ou "muito superficial" foi considerado "Pequeno", en- 
quanto conhecimento "profundo" ou "muito profundo" foi considerado "Grande”. Analogamente, a visualização gráfica do grau de influência declarado seguiu o mesmo critério. Acreditamos que a adoção de dois níveis nas extremidades permitiu uma distribuição mais variada das respostas ao questionário. Se houvesse apenas três níveis a serem marcados, o nível "intermediário" ou "Médio" poderia ser sobrecarregado, distorcendo a amostragem.

${ }^{16}$ Algumas delas, como já destacado anteriormente, não são “textos fundadores” e podem, portanto, ser consideradas como desdobramentos das matrizes históricas.

${ }^{17}$ Como bem observou um dos respondentes mais jovens, por vezes trabalha-se com música no computador quotidianamente, utilizando samplers, instrumentos virtuais e sequenciadores, porém talvez nem mesmo faça sentido dizer que se está fazendo Computer Music. Por outro lado, um trabalho de tratamento, filtragem, corte e montagem de material obtido por meio da gravação de sons ambientais talvez esteja muito próximo da Musique Concrète, ainda que tenha sido realizado todo em computador, desde o momento da gravação até o da mixagem final. É aqui que aparece a importância dos procedimentos e dos conceitos que norteiam a realização de uma obra, como vimos nas primeiras seções deste estudo, para uma melhor compreensão do quadro estético da música eletroacústica brasileira contemporânea.

\section{Referências}

BOURDIEU, P. La Distinction. Paris: Editions de Minuit, 1979.

. Les Règles de l’Art. Paris: Éditions du Seuil, 1998.

CACCIATORE, O. G. Dicionário Biográfico de Música Erudita Brasileira. Rio de Janeiro: Forense, 2005.

HEIDEGGER, Martin. “The Question Concerning Technology” In: KRELL, David Farrell (ed.) Basic Writings: From Being and Time (1927) to The Task of Thinking (1964). New York: Harper and Row, 1977.

HENNION, Antoine. La Passion Musicale. Paris: Métailié, 2007.

LATOUR, Bruno. Changer de Société, refaire de la sociologie. Paris: La Découverte, 2007.

MANNHEIM, Karl. "The Problem of Generations” in: Essays on the Sociology of Knowledge. New York: Oxford University Press, 1952, p. 276-322.

MARIZ, V. História da Música no Brasil. 5. ed. Rio de Janeiro: Nova Fronteira, 2000.

MEIHY, José Carlos S. B. Manual de História Oral. 5. ed. São Paulo: Editora Loyola, 2005.

MOLINO, Jean. "Fait musical et sémiologie de la musique”. In: Musique en jeu, n.17, p. 37-62, 1975.

NATTIEZ, Jean-Jacques. Fondements d’une sémiologie de la musique. Paris: Union Générale d'Éditions, 1975.

NEVES, J. M. Música Contemporânea Brasileira. São Paulo: Ricordi, 1981.

RICOEUR, Paul. La Mémoire, l'Histoire, l’Oubli. Paris: Éditions du Seuil, 2003.

SILVA, F. (ed.). XX Bienal de Música Brasileira Contemporânea. Rio de Janeiro: Funarte, 2013.

SPOLADORE, Marina. "A Aplicação de um Modelo Semiológico de Análise em uma Análise de Savanas, de Almeida Prado”. 2008. Disponível em: http://seer.unirio.br/index.php/coloquio/ article/viewFile/220/208. Último acesso em: 26/11/2013

SWIDLER, Ann. "Culture in Action: Symbols and Strategies". In: American Sociological Review. v.51, n.2, Abr., 1986. 
VELLOSO, Rodrigo Cicchelli, et al. "Referenciais Teóricos da Música Eletroacústica Brasileira Contemporânea: apontamentos iniciais”. In: Anais do $8^{\circ}$ Colóquio de Pesquisa do Programa de Pós-Graduação em Música da UFRJ., 2008, Rio de Janeiro: Programa de Pós-Graduação em Música da UFRJ, (no prelo).

. et alii. "Referenciais Teóricos da Música Eletroacústica Brasileira Contemporânea: acerca de um questionário". In: CONGRESSO DA ASSOCIAÇÃO NACIONAL DE PESQUISA E PÓSGRADUAÇÃO EM MÚSICA, XIX., 2009, Curitiba. Anais. Curitiba: ANPPOM, 2009, p. 501-504.

Rodrigo Cicchelli Velloso - Professor Associado junto ao Departamento de Composição da Escola de Música da Universidade Federal do Rio de Janeiro, onde atua desde 1998, e integrante do grupo interdisciplinar Concha da UFRJ. Bacharel em Composição Musical pelo Instituto Villa-Lobos da UNIRIO (1984-1990). PhD em Composição de Música Eletroacústica pela University of East Anglia (1991-1996). Especialização no Cursus de Composition et d'Informatique Musicale do IRCAM (1995-1997). Atualmente concluindo Bacharelado em Flauta Transversa pelo IVL/UNIRIO (2010-). Produz e apresenta Eletroacústicas pela Rádio MEC FM desde 2010.

Frederico Machado de Barros - Doutor em Sociologia pela Universidade de São Paulo (2013), possui graduação em História pela Universidade Federal Fluminense (2003) e mestrado em História Social da Cultura pela Pontifícia Universidade Católica do Rio de Janeiro (2006). Atualmente é professor substituto de Etnomusicologia na Universidade Federal do Rio de Janeiro. Tem experiência nas áreas de Sociologia da Cultura e da Música, História, Musicologia e Etnomusicologia, atuando principalmente com os seguintes temas: música, pensamento social brasileiro e movimentos artísticos nos séculos XX e XXI. 